\title{
The Relation between Morality and Organizational Commitment of the Teachers with the Training Quality Level of Students in the City of Tehran Girls' Secondary Schools
}

\author{
Raheleh Safikhani ${ }^{1 *}$
}

\section{ABSTRACT}

Introduction: Having two indices of professional morality and organizational commitment from teacher's side is effective in the optimum output of the educational system. Purpose: The present research was done with the purpose of examining the relation between morality and organizational commitment of teachers with the quality of educational services of students. Method: For this means in the format of a comparative design in the area of descriptive studies and in terms of functional nature, five thousand and seven hundred and seventy five students $(\mathrm{N}=5775)$ and 385 teachers (ages 26-58 with a mean age of: 38/11) resident of Tehran were chosen by the multistage cluster sampling method. The method of gathering of the data was done by survey. In terms of assessment of organizational commitment the Allen and Meyer questionnaire, in terms of evaluation of organizational behavior Kadar questionnaire and to assess the index of quality of education the researcher's questionnaire were used. The data gathered were analyzed by the Pearson correlation test, F test and multivariable regression test. Findings: The analysis of the data was favorable with the history of research showing a relation between morality ( $\mathrm{r}=0 / 59)$ from one side and behavioral commitment $(\mathrm{r}=0 / 47)$ from another side with the component of quality of education $(\mathrm{p}<0 / 0001)$, in other words behavior and behavioral commitment have explained each respectively 0/408 and 0/311 of the variance of the quality of education. Conclusion: The result of this research can be functionally used in the design of massive educational perspectives.

Keywords: Morality, Organizational Commitment, Educational Services Quality, Teaching.

Today morality is one of the discussions under consideration of researchers and is the necessity and need of a healthy society. Some of the behavior of managers and employees are effected by moral values. Weak organizational morality has an adverse effect on attitude, individual and

\footnotetext{
${ }^{1}$ M.A in Educational Technology, Islamic Azad University of Garmsar Branch, Garmsar, Iran *Responding Author

(C) 2016 I R Safikhani; licensee IJIP. This is an Open Access Research distributed under the terms of the Creative Commons Attribution License (http://creativecommons.org/licenses/by/2.0), which permits unrestricted use, distribution, and reproduction in any Medium, provided the original work is properly cited.
} 
group function of the organization (Alvani et al, 2010). Organizational morality in fact is the description and assessment of rooted values and the search for mechanisms of morality of functions (Carolyn and Kris, 2006). Another important component which makes an organization become the head of another organization is organizational commitment. Thereby considering the category of commitment and loyalty of human resources towards organization is one of the serious concerns of organizations' managers (Bagheri et al, 2009). According to the definition of Meyer and Allen it has three major components, emotional, normative and continuous. Emotional commitment implies the attachment of individual feelings to the organization. Continuous commitment contains the definition of willingness to stay in the organization and normative commitment implies to the obligation of feelings towards the organization (Meyer and Herskowich, 2001).

The committed force makes the path of growth and ascendancy of the organization possible. From the emotional view point organizational commitment is considered to be an emotional dependency. According to this method, the individual who is extremely committed obtains its identity from the organization, participates in the organization and blends with it and enjoys being its member (Saroghi, 1996). Committed employees often have relation and connection with the values of the organization (Valentine et al, 2002). One of the effective organizations on the body of cultural and training of the society, is education and training. The grand position of this organization, makes its need for the committed and moral organizational force obvious. The organization of education and training in order to reach its goals, meaning the training and education of people is in need of activist teachers, committed and compassionate, committed teachers perform their duties to the best form and cause increased efficiency of the educational system.

Even with the width of organization of this organization in various levels of management, unfortunately in the direction of reform and improvement of the educational processes effective measures have not formed. These measures need more consideration than before for the quality of education (Yadegarzadeh, 2000). The quality of education, is the specifications of an educational system which can be favorable or unfavorable which this matter, shows the relativity of this concept (Yamni, 1995). According to the last report of the institution of research of Pirls and Timss the position of Iran in the year 2001 from among the 35 participating countries was in the $32^{\text {nd }}$ place and in the year 2006 from among 45 world educational systems was in the $40^{\text {th }}$ place. According to this estimation the average performance of Iranian students in the year interval of 2001 to 2006 has had an improvement of 7 scores but this improvement is not meaningful in terms of statistical indices (Karimi, 2006). 
Therefore regarding the studies performed in relation with organizational commitment and behavior of employees, it shows the importance and bold role of human resources as the most valuable capitals of each organization. Organizational behavior is an effective factor in the function of organizations. On the other hand commitment is one of the major parts of behavior such that consideration and institutionalizing of moral behavior in the organization causes increase in the commitment of employees, individual and organizational growth and ascendancy thereafter. Organizational good behavior has a positive and excellent effect on activities and results of the organization. Therefore commitment is the key factor in the relation between individual and the organization, the committed people adhere more to the values and goals of the organization and play an active role in the organization and leave the organization lesser and have lesser absence.

The organization of education and training as the largest governmental organization for the exact performance of developmental programs and its improvement and also improvement of the educational services quality needs teachers committed and with morals, in fact increase in the quality of education in schools is achieved in addition to considering the resources and equipment, from the major factor in the system of education meaning the "teacher". Teachers can play the most important role in the availability of appropriate conditions for the activities of learning. Therefore, considering organizational behavior and commitment teachers can open appropriate paths in terms of improving quality of education of schools. As a result in this research we will examine the relation between organizational morality and commitment of teachers with the quality of educational services of students at the city of Tehran girls' secondary school.

\section{Ethical Principles}

In this study, the informed consent was obtained without coercion, threat, enticement and seduction and their decision to refuse or accept to participate in the study were respected. It was also tried that the research methods do not contradict with the religious and cultural principles of the participants and the participants were respected in all stages of design, implementation and reporting in terms of human dignity, respect and protection of their physical and mental integrity so that conducting the research would not delay in the process of medical care for the participants.

\section{Statistical society and estimate of sample size}

The current research has two statistical societies. 1- All of the woman teachers of the city of Tehran public secondary schools which have education higher than diploma which are thousand people in total. 2- All girl students of the city of Tehran public secondary schools, which are in total one hundred and twelve persons. Estimate of sample size with respect to the unlimited society and existing of the scale of Likert was calculated. Therefore in this research sample size 
The Relation between Morality and Organizational Commitment of the Teachers with the Training Quality Level of Students in the City of Tehran Girls' Secondary Schools

was considered to be 385 persons. The sample size of the students was 15 students per each teacher which in total reached 5775 person.

Table 1- estimate of the sample size

\begin{tabular}{|c|c|}
\hline Size of society & Unlimited \\
\hline $\begin{array}{c}\text { Precision of } \\
\text { estimate }\end{array}$ & $0 / 05$ \\
\hline Sample size & 385 \\
\hline
\end{tabular}

\section{METHOD}

\section{Data collection}

This research in terms of functional purpose and in terms of method of performance is descriptive-survey. The method of sampling was random and from the stratified cluster type. The method of gathering of data in this research was of the field method in which questionnaires used were distributed among teachers and students of schools under research. The questionnaires were completed in person and were gathered by the research performers. Thereafter the data were composed and analyzed by the SPSS software. For the purpose of gathering of data in this research the following questionnaires were used.

\section{Instruments}

- Organizational commitment questionnaire: This questionnaire is codified with the purpose of examination of the organizational commitment dimensions. In this tools, organizational commitment with respect to the three dimensions of emotional, continuous commitment and normative commitment in the spectrum of Likert and in the form of five degree scale is examined and has high validity, the reliability coefficient of the complete questionnaire according to Cronbach's alpha calculations was estimated to be 0/97 and the coefficients related to the components of emotional commitment, continuous commitment and normative commitment were estimated 0/86, 0/85 and 0/92 respectively (Meyer and Allen, 1997).

\section{- Organizational morality questionnaire}

- Educational services quality questionnaire: For the purpose of examination of the index of education quality the item questionnaire developed by the researcher was used. The Cronbach's alpha of this questionnaire was calculated to be $0 / 944$.

\section{RESULTS}

Results in two areas of descriptive in the format of presentation of average and standard deviation and also inferential in the format of Pearson's correlation parametric test, $\mathrm{F}$ test and 
The Relation between Morality and Organizational Commitment of the Teachers with the Training Quality Level of Students in the City of Tehran Girls' Secondary Schools

stepwise regression analysis in the software SPSS environment edition 19 was composed and analyzed which are shown in the tables below.

\section{Demographic features of the participants}

79,5 percent of people responding had Bachelor's degree. About 20 percent of the people participating in the research had Master's degree and above and 0,5 percent of the participants also had Associate degree or lower. Most category of abundance in terms of employment history is related to the history of 11-15 years with 94/8 (365 person out of 385 person responsive), in other words about 94,8 percent of people responsive have history of employment of 11 to 15 years.

\section{Average and standard deviation}

Table 2- Average and standard deviation of participant's scores in the triple components of research

\begin{tabular}{|c|c|c|}
\hline index & average & SD \\
\hline Morality & $11 / 27$ & $1 / 17$ \\
\hline Organizational commitment & $14 / 94$ & $2 / 01$ \\
\hline Educational quality & $16 / 23$ & $3 / 11$ \\
\hline
\end{tabular}

Table 2, shows the average and standard deviation of the testable scores in the three components of Morality, organizational commitment and educational quality.

\section{Pearson's correlation test}

Table 3- Results of the Pearson's correlation test

\begin{tabular}{|c|c|c|c|}
\hline Predictor variable & Criterion variable & $\begin{array}{c}\text { Coefficient of } \\
\text { correlation }\end{array}$ & P-value \\
\hline $\begin{array}{c}\text { Educational } \\
\text { quality }\end{array}$ & Morality & $0 / 59$ & $0 / 000$ \\
\hline & $\begin{array}{c}\text { Organizational } \\
\text { commitment }\end{array}$ & $0 / 47$ & $0 / 000$ \\
\hline
\end{tabular}

With respect to the results in table 3, Pearson's correlation test show that between the two components of behavior with educational quality and also organizational commitment with quality of education there is a meaningful correlation $(\mathrm{p}<0 / 0001)$. For the purpose of examination of each component's share in explaining variance of the index of educational quality, step by step regression analysis test was used, the results of this test is presented in table 5: 
The Relation between Morality and Organizational Commitment of the Teachers with the Training Quality Level of Students in the City of Tehran Girls' Secondary Schools

Analysis of the step by step regression

Table 4: Results of the step by step multivariable regression analysis test

\begin{tabular}{|c|c|c|c|c|}
\hline $\begin{array}{c}\text { Predictor } \\
\text { variable }\end{array}$ & $\begin{array}{c}\text { Criterion of } \\
\text { variable }\end{array}$ & $\mathbf{B}$ & sig & $\mathbf{R}^{2}$ \\
\hline $\begin{array}{c}\text { Educational } \\
\text { quality }\end{array}$ & Morality & $0 / 408$ & $0 / 000$ & $0 / 719$ \\
\hline & $\begin{array}{c}\text { Organizational } \\
\text { commitment }\end{array}$ & $0 / 311$ & $0 / 000$ & \\
\hline
\end{tabular}

$\mathrm{F}=16 / 73$

\section{Calculation of the equation of the regression line}

The results of the step by step multivariable regression analysis test show that the components of Morality and organizational commitment respectively 0/408 and 0/311 and in total 0/719 of the variance of the index of educational quality are explained in the sample under research. The function of multivariable regression of educational quality in terms of dimensions of Morality and organizational commitment are as follows:

$Y_{i}=\beta_{0}+B X 1_{i}+B X 2_{i}+u_{i}$

$Y_{i}=7+0 / 408 X 1_{i}+0 / 311 X 2_{i}$

\section{DISCUSSION}

The study viewed was an effort in the examination and prediction of the indices beneath the quality of education. The findings showed that the two components of Morality and commitment of teachers each in a meaningful way explain part of the variance of quality of educational services in students. About the importance and relation among the indicated indices it has been mentioned in previous studies. Most of the history of research of committed organizational professors means the story of the meaningful positive relation between the two indices of Morality and quality of education. This appropriateness of performance for the committed organizational professors in other words, is teaching of quality for them, for a better prediction can be programmed to improve the learning of students. These findings with the results of several research activities performed are favorable on this issue. In Schroder's research (2008) between the component of organizational commitment and quality of education a meaningful positive relation was obtained. In another study Nazem and Ghaed Mohammady (2009) reported that organizational commitment can predict the quality of educational services. The results of the study of Rejaipour and Bahrami (2006) also express the relation between the mentioned indices. Also findings of this research is favorable with the results of the studies of Tomositis (2006) and Smank and coworkers (2009). 
On the other hand and in more extended dimensions we can say that organizational commitment in total has a meaningful relation with the spectrum of variables increasing efficiency and performance. In this matter the results of the studies of Boatman and Strawser (1984), Shawni (1997), Bowlin (1994), Ruygar (1991), Vedford (1982), Ixe (2005), Chung and Lee (2006), Linguard and Lin (2004) show variable performance of organizational commitment and its relation with variables increasing efficiency. In this respect eligibility and teaching experience of professors with the students' educational improvement have a linear positive relation (Hanooshk et al, 2005). On the other hand research evidences express the relation between components of behavior with educational quality index. A relation which can effect massive educational strategies and change the efficiency of teaching. In this respect the results of the current study show a meaningful positive relation between the two mentioned indices. These findings are favorable with the results of previous studies regarding the relation between behavior and educational quality. For example, the current findings are favorable with the studies of Rahimi and Aghababai (2012), Ekvasi (2004) and Witz (2010) regarding the relation between professional behaviors of professors with the quality of educational services and are unfavorable with the results of research of Valentine (2008). One of the reasons of this unfavorability can be due to the difference in the statistical society under study. According to the findings obtained we can say that the index of morality in the members of the science committee is an effective component on quality output of educational services in students. What was considered was a study performed with the purpose of examining the relation between the two index of behavior and organizational commitment with organizational services quality and the results expressing a meaningful share of each of the two components of behavior and commitment in predicting the levels of educational quality. The mentioned findings can have an application aspect and can be efficient in adjusting designs of the advancement of the educational system and understanding of the challenges related to it.

\section{RESEARCH IMPLICATIONS}

Considering that organizational behavior has the most effect on the continuous commitment of employees hence it is suggested for the means of increasing of continuous commitment the moral foundations be considered. Emphasize organizational moral principles in the programs of improving of the organization (examination and training of employees) and their development for all employees in any level. Integration of ethical standards in the organization and also development of ethical charters.

\section{LIMITATIONS}

The most important limitation of research which arise from the specific criteria of the behavioral sciences research, are limitations for example of written questionnaire, lack of cooperation and subjective impressions of testable which effect the correct response to the questions. 
The Relation between Morality and Organizational Commitment of the Teachers with the Training Quality Level of Students in the City of Tehran Girls' Secondary Schools

\section{Acknowledgments}

The author has the deepest thanks and appreciation from all of the people which participated in this study and helped in facilitating the process of research.

\section{Conflict of Interests}

The author declared no conflict of interests.

\section{REFERENCES}

Abdolazim, K. Examination of the results of the international study of improving the reading skills of Pearls.

Ampofo, A., Mujtaba, B., Cavico, F., \& Tindall, L. (2011). The relationship between organizational ethical culture and the ethical behavior of employees: A study of accounting and finance professionals in the insurance industry of United States. Journal of Business \& Economics Research (JBER), 2(9).

Bateman, T. S., \& Strasser, S. (1984). A longitudinal analysis of the antecedents of organizational commitment. Academy of management journal, 27(1), 95-112.

Bolin, L. K. (1994). The post-merger environment: the relationship between perceived personal control and organizational commitment . Dissertation Abstract Ph.D. California School of Professional.

Chang, S.-C., \& Lee, M.-S. (2006). Relationships among personality traits, job characteristics, job satisfaction and organizational commitment-an empirical study in Taiwan. The Business Review, 6(1), 201-207.

Ian Carlin, B., \& Gervais, S. (2009). Work ethic, employment contracts, and firm value. The Journal of Finance, 64(2), 785-821.

Lingard, H., \& Lin, J. (2004). Career, family and work environment determinants of organizational commitment among women in the Australian construction industry. Construction Management and Economics, 22(4), 409-420.

Meyer, J. P., \& Herscovitch, L. (2001). Commitment in the workplace: Toward a general model. Human resource management review, 11(3), 299-326.

Mohammad, Y. D. S. (2001). Analysis of the meaning of quality in public education and training of Iran.

Moslem, B and, Elah, T. R. Examination of the effect of organizational commitment on the performance of organizations.

Nazem, F. and Ghaedmohammadi, M.(2009); "Organizational Commitment and its Component in Islamic zad University”; Journal of Modern Thoughts in Education, Vol. 4 , No.1, pp.11-28 (in Persian).

Rahimi H, Aghabaee R. (2013). Relationship between organizational culture and professional ethics faculty at University of Kashan. Journal of Medical Education Strategies; 6(2). 
The Relation between Morality and Organizational Commitment of the Teachers with the Training Quality Level of Students in the City of Tehran Girls' Secondary Schools

Rajaeipour, S., \& BAHRAMI, S. (2008). relationship between clarity of role and job commitment among the personnel of the colleges of Isfahan university of medical sciences.

Saroghi, Mohammad. (1375), Examination of the effect of organizational commitment on the willingness to leave the service, thesis of the Masters in public management, University of management, Tehran university.

Schoeny, A. C. (1997). The relation of person-environment fit to measures of job satisfaction and organizational commitment for volunteers in the nonprofit sector.

Schroder, R. (2008). Predictors of organizational commitment for faculty and administrators of a private Christian university. Journal of research on Christian education, 17(1), 81-97.

Seyed Mehdi, A, H. P and, Ali, D. Analysis of the organizational behavior of employees using the Moral Compass Model.

Smeenk, S. G., Eisinga, R. N., Teelken, J., \& Doorewaard, J. (2006). The effects of HRM practices and antecedents on organizational commitment among university employees. The International Journal of Human Resource Management, 17(12), 2035-2054.

Tamosaitis, W. L. (2006). The Relationship Between Employee Performance Ratings and the Three Components of Organizational Commitment for Technical Personnel in a Project Environment: A Dissertation.

Valentine, S., \& Fleischman, G. (2008). Professional ethical standards, corporate social responsibility, and the perceived role of ethics and social responsibility. Journal of Business Ethics, 82(3), 657-666.

Valentine, S., Godkin, L., \& Lucero, M. (2002). Ethical context, organizational commitment, and person-organization fit. Journal of Business Ethics, 41(4), 349-360.

Vitez O. (2010). What is the relationship between corporate culture and ethics? Journal of Bus Ethics; 100(2): 515-30.

Weatherford, Smiley William, JR., (1982). Communication, Job satisfaction, and organizational commitment in the hospital environment. Dissertation Abstract Ph.D. University of Georgia.

Xie, Di. (2005). Exploring organizational learning culture, job satisfaction, motivation to learn, organizational commitment, and internal service quality in a sport organization . Dissertation Abstract Ph. D. The Ohio University.

How to cite this article: R Safikhani (2016), The Relation between Morality and Organizational Commitment of the Teachers with the Training Quality Level of Students in the City of Tehran Girls' Secondary Schools, International Journal of Indian Psychology, Volume 3, Issue 4, No. 57, ISSN 2348-5396 (e), ISSN: 2349-3429 (p), DIP: 18.01.022/20160304, ISBN: 978-1-365-239939 